\title{
Reflexões sobre as concepções e expectativas de professores de Educação Física acerca de um curso de especialização em educação na cultura digital
}

\author{
Reflections on the conceptions and expectations of Physical Education teachers about a \\ specialization course in education in digital culture
}

Reflexiones sobre las concepciones y expectativas de los profesores de Educación Física sobre un curso de especialización en educación en cultura digital

\author{
Juliano Silveira ${ }^{\text {I }}$ Giovani De Lorenzi Pires ${ }^{\text {II }}$
}

\begin{abstract}
Resumo
Este artigo objetiva refletir sobre as concepções e expectativas de professores de Educação Física quanto a sua participação em um Núcleo de estudos, que aborda o componente curricular a partir da perspectiva da educação na cultura digital. Os dados produzidos para este estudo de caso de caráter qualitativo são oriundos de entrevistas semiestruturadas, realizadas com 10 professores/ cursistas. Para tratamento dos dados, foi utilizada a análise de conteúdo. Os resultados revelam expectativas ligadas à pouca familiaridade com as temáticas relacionadas à abordagem das tecnologias nas aulas de Educação Física, indicando, assim, a necessidade de investimentos em termos de formação continuada.
\end{abstract}

Palavras-chave: Educação Física; Formação de Professores; Cultura Digital

\begin{abstract}
This article aims to reflect on the conceptions and expectations of Physical Education teachers regarding their participation in a study core that addresses its curricular component from the perspective of education in digital culture. The data produced for this qualitative case study come from semi-structured interviews conducted with 10 teachers/participants. For data analysis, content analysis was used. The results reveal expectations linked to little familiarity with the themes related to the approach to technologies in Physical Education classes, thus indicating the need for investments in terms of continuing education.
\end{abstract}

Keywords: Physical Education; Teacher training; Digital Culture

\footnotetext{
${ }^{\text {I } U n i v e r s i d a d e ~ F e d e r a l ~ d e ~ S a n t a ~ C a t a r i n a ~-~ U F S C ~-~ e-m a i l: ~ j u l i a n o s i l v e i r a 1981 @ g m a i l . c o m ~-~ E n d e r e c ̧ o: ~ R . ~ L e o p o l d o ~ A r r u d a ~-~ S a n t o ~ A n t o ̂ n i o ~ d e ~ P a ́ d u a, ~}$ Curitibanos - SC, 89520-000.

${ }^{\mathrm{I}}$ Universidade Federal de Santa Catarina - UFSC - delorenzi57@gmail.com
} 


\section{Resumen}

Este artículo tiene como objetivo reflexionar sobre las expectativas y concepciones de los maestros de Educación Física con respecto a su participación en un grupo de estudio que aborda su componente curricular desde la perspectiva de la educación en cultura digital. Los datos producidos para este estudio de caso cualitativo provienen de entrevistas semiestructuradas realizadas con 10 docentes participantes/profesores del curso. Para el análisis de datos, se utilizó el análisis de contenido. Los resultados revelan expectativas vinculadas a la poca familiaridad con los temas relacionados con el enfoque de las tecnologías en las clases de educación física, lo que indica la necesidad de inversiones en términos de educación continua.

Palabras clave: Educación física; Formación de profesores; Cultura digital

\section{Introdução}

A contemporaneidade tem sido marcada por uma dinâmica cultural, na qual as tecnologias digitais de informação e comunicação (TDIC) acabam assumindo destaque, permeando as mais diferentes atividades do cotidiano das pessoas. Trata-se de um "processo crescente de reorganização das relações sociais mediadas pelas tecnologias digitais, afetando em maior ou menor escala todos os aspectos da ação humana" (PRETTO; ASSIS, 2008, p.78), caracterizando o ingresso da população em uma cultura digital (RAMOS et al, 2013).

Nessa perspectiva, a emergência de uma cultura digital implica a necessidade de se repensar a educação escolar e o papel dos professores e de suas práticas pedagógicas frente a uma nova forma de organização, produção e acesso aos conhecimentos. Isso precisa ocorrer especialmente devido ao papel preponderante que esses meios tecnológicos assumem nas vivências cotidianas das crianças e jovens que frequentam instituições escolares (BUCKINGHAM, 2012). Dessa maneira, se a educação institucionalizada é chamada a "reinventar-se", a própria formação docente, na esfera das licenciaturas, passou por mudanças em suas diretrizes, visando contemplar aspectos dessa nova dinâmica cultural. Além disso, um movimento semelhante tem ocorrido no âmbito da formação continuada de professores (BIANCHI, 2014).

Em se tratando especificamente da Educação Física escolar, a necessidade de uma abordagem didática e pedagógica, que contemple as TDICs, justifica-se pelo fato de que as representações sociais referentes às práticas corporais, pelas quais esse componente curricular se ocupa na escola, são em grande parte produzidas e compartilhadas no espaço-tempo social em que se configuram como uma cultura digital (PIRES; LAZAROTTI FILHO; LISBOA, 2012). 
Tendo em vista tal demanda, em termos de formação docente, foi produzido e ofertado o curso de especialização em Educação na cultura digital ${ }^{1}$, desenvolvido pela Universidade Federal de Santa Catarina e destinado a professores de escolas públicas de Santa Catarina, visando a qualificação da ação docente com as tecnologias ${ }^{2}$. Esse curso teve caráter multidisciplinar e estruturou-se com base em Núcleos de estudos de especificidades didático-pedagógicas dos diferentes componentes curriculares. Dentre esses núcleos, foi oferecido um Núcleo específico de Educação Física e TDIC (NEEF), em que sua produção e oferta ficou a cargo do LaboMídia/ UFSC ${ }^{3}$ (PIRES et al, 2017).

As temáticas desenvolvidas na especialização, assim como no Núcleo específico de Educação Física e TDIC, eram recentes e pouco exploradas no âmbito da formação dos docentes que participaram desta proposta formativa. Assim, investigar as expectativas desses sujeitos quanto a sua participação no curso tende a ser um exercício analítico interessante. Essa estratégia revela uma série de questionamentos, angústias em relação ao cotidiano pedagógico, bem como concepções acerca das tecnologias e suas relações com a Educação Física escolar, que podem servir como base para definir ações formativas para os docentes. Dessa forma, o objetivo do presente artigo é refletir sobre as expectativas e concepções de professores de Educação Física quanto a sua participação em um Núcleo de estudos que aborda o componente curricular a partir da perspectiva de uma educação na cultura digital.

\section{METODOLOGIA ${ }^{4}$}

Este artigo pode ser caracterizado metodologicamente como oriundo de um estudo de caso, com abordagem qualitativa, que adota como objeto a oferta-piloto do Núcleo específico Educação Física e TDIC

\footnotetext{
${ }^{1} \mathrm{O}$ curso foi ofertado na modalidade de ensino à distância, em caráter piloto, pelo Departamento de Metodologia de Ensino (MEN) do Centro de Ciências da Educação da Universidade Federal de Santa Catarina e foi destinado para professores de escolas públicas de Santa Catarina entre os anos de 2014 e 2016.

2 Para mais informações sobre o curso, acessar: http://educacaonaculturadigital.mec.gov.br e http://catalogo.educaconaculturadigital.mec.gov.br

${ }^{3}$ O Laboratório e Observatório da Mídia esportiva (LaboMidia), do Centro de Desportos da Universidade Federal de Santa Catarina, possui representatividade no cenário nacional da área de Educação Física em relação aos estudos sobre mídias, tecnologias e Mídia-Educação Física. É fruto de uma proposta de trabalho coletivo, construída ao longo dos últimos 17 anos, com ações visando introduzir a cultura midiática na formação acadêmica no âmbito da pesquisa, ensino e extensão em Educação Física. Dentre suas ações, o LaboMídia atua oferecendo disciplinas no âmbito da graduação e pós-graduação; desenvolve investigações individuais e coletivas; oferece oficinas de capacitação; fornece suporte à produção de audiovisuais; é responsável pela editoração da Revista Motrivivência; mantém blogs temáticos e um repositório ligado ao Ministério do Esporte com expressiva visibilidade na área da Educação Física. Além disso, o grupo tem papel fundamental na articulação do GTT Comunicação e Mídia do Colégio Brasileiro de Ciências do Esporte (CBCE) e possui ampla produção acadêmica representada por teses, dissertações, monografias, artigos publicados em periódicos, livros e trabalhos apresentados em eventos.

${ }^{4} \mathrm{O}$ projeto de pesquisa foi submetido à avaliação do Comitê de Ética em Pesquisa com Seres Humanos (CEPSH), da Universidade Federal de Santa Catarina (UFSC), e aprovado sem restrições, com o número 57911816.9.0000.0121
} 
no âmbito do curso de Especialização em educação na cultura digital. De acordo com Minayo (2012, p. 37), "a abordagem qualitativa aprofunda-se no mundo dos significados das ações e relações humanas, um lado não perceptível e não captável em equações, médias e estatísticas”, permitindo explorar a complexidade das questões referentes ao tema investigado. Epistemologicamente, procura-se uma aproximação com os preceitos da abordagem sócio-histórica que consiste "numa preocupação de compreender os eventos investigados, descrevendo-os e procurando as suas possíveis relações, integrando o individual com o social" (FREITAS, 2007, p.28).

O processo de produção dos dados para a investigação que serve de base para este artigo contemplou entrevistas de caráter semiestruturado, realizadas logo após o término do Curso de Especialização ${ }^{5}$. Essa técnica permite que o pesquisador aborde questões oriundas das informações repassadas pelos entrevistados, para além do roteiro prévio de entrevista, possibilitando maior flexibilidade na obtenção de dados junto aos sujeitos da pesquisa.

Os sujeitos participantes da pesquisa são 10 professores e professoras de Educação Física/ cursistas ${ }^{6}$ do NEEF, que participaram de todas as etapas do Curso de Especialização ${ }^{7}$, desde os núcleos iniciais, até o Trabalho de conclusão de curso. Cabe destacar que os professores participantes da pesquisa eram oriundos de diferentes regiões de Santa Catarina, e, por isso, as entrevistas foram realizadas predominantemente à distância, via Skype, gravadas e transcritas para posterior análise.

Por último, em se tratando da ferramenta metodológica adotada para a interpretação dos dados produzidos em campo, optamos pela análise de conteúdo. A análise de conteúdo pode ser identificada como uma técnica de pesquisa oriunda das ciências humanas, caracterizada como uma atitude de vigilância crítica, na qual se nega uma leitura simples do real e se procura estabelecer compreensão dos fatos ou das mensagens comunicativas manifestadas para além dos seus significados imediatos (BARDIN, 2009). Em outras palavras, pode ser concebida como um conjunto de técnicas de análise das comunicações, que visa obter, por meio de procedimentos sistemáticos e objetivos de descrição do conteúdo das mensagens, indicadores que permitam a inferência de conhecimentos relativos às condições de produção/ recepção dessas mensagens.

\footnotetext{
${ }^{5} \mathrm{O}$ curso foi encerrado em agosto de 2016.

${ }^{6}$ Os sujeitos participantes da pesquisa são identificados nos trechos de depoimentos como PC.

${ }^{7}$ A duração do curso de especialização previa incialmente 360 horas, distribuídas ao longo de 18 meses, contudo, em virtude de algumas interrupções, devido ao problema de repasse de recursos para o pagamento de bolsas, o curso se estendeu por aproximadamente 24 meses. O corpo docente envolvido na oferta do curso contava com, aproximadamente, 120 profissionais entre professores e tutores e foi iniciado contemplando 800 professores/cursistas de diferentes componentes curriculares. $\mathrm{O}$ Núcleo específico Educação Física e TDIC teve a duração de 60 horas e iniciou suas atividades com 17 cursistas. Contudo, tendo em vista algumas desistências, apenas 10 cursistas o concluíram e puderem passar para a etapa final (TCC).
} 


\section{Resultados e discussão}

O primeiro elemento a ser destacado sobre as expectativas de realização do curso de especialização em educação na cultura digital é a própria curiosidade dos professores/ cursistas quanto ao conceito de cultura digital. De acordo com o professor/ cursista 10,

"O que me chamou a atenção foi o próprio nome do curso, né?! Educação na cultura digital, então já me chamou a atenção o nome do curso e eu sempre fui muito curiosa e aí eu quis ver o que era isso" (PC 10).

A curiosidade inerente ao desconhecimento terminológico do conceito-chave do curso também se revela como uma demanda de formação continuada dos professores para atuar pedagogicamente nas escolas com as tecnologias. De fato, de acordo com Carvalho Junior (2009, p.09), “Cultura digital é um termo novo, emergente. Vem sendo apropriado por diferentes setores, e incorpora perspectivas diversas sobre o impacto das tecnologias digitais e da conexão em rede na sociedade". Por isso, embora as pessoas tenham consciência da presença das TDICs no seu cotidiano, e da mudança cultural decorrente dos diferentes usos que são feitos dessas ferramentas, parece razoável que o termo cultura digital ainda não seja citado com frequência nas rodas de conversa, mesmo online, e entre os docentes nas escolas.

Algumas expectativas também se voltavam para o próprio funcionamento do curso de especialização, que seria oferecido na modalidade EaD. Segundo o professor/ cursista 3,

"Então...eu confesso que no início minhas expectativas e ansiedades em relação ao curso eram mais sobre como o curso ia funcionar. Como seriam os trabalhos, atividades... a postagem na plataforma...se teriam atividades práticas para aplicar em sala de aula" (PC 3).

Pode-se afirmar tal expectativa oriunda da realização de um curso na modalidade à distância, que, até então, constituía nova experiência para o professor/ cursista. Nesse caso, questões práticas ligadas à realização e postagem das atividades, as suas próprias características, e a necessidade, ou não, de intervenções no ambiente escolar, tendem a ser comuns, uma vez que demandam tempo e a própria organização dos docentes para a sua realização. Como os professores não contariam com horas liberadas especificamente para a realização do curso, e, talvez fosse difícil articular os diferentes momentos de hora- 
atividade $^{8}$ dos docentes, uma vez que o curso envolveria a realização de atividades coletivas, essa parece ser uma preocupação plenamente justificada.

Ainda na esfera das preocupações que antecederam a realização do curso, destacava-se a questão da aceitação da integração das TDICs às aulas, tanto por parte dos alunos, que participariam diretamente das propostas a serem desenvolvidas; quanto por parte dos demais docentes, que ainda possuem resistências quanto à presença das tecnologias na escola. Por isso, por exemplo, o professor/ cursista 3 se questionava,

"Ahhh, como seria sua aceitação pelos alunos e demais professores da escola, pois a escola ainda tem dificuldades em se adaptar a essa inovação tecnológica” (PC3).

Essa é uma preocupação/ expectativa de que, possivelmente, na sua instituição escolar, há uma postura de resistência por parte de outros professores que "não veem com bons olhos" as tecnologias na escola. E, soma-se a isso o dado apontado na pesquisa de Mendes (2009), de que os professores temem a reação dos alunos frente à proposta de integração das TDICs às aulas, pois estes "geralmente resistem às propostas inovadoras" (2009, p.179).

De fato, a integração das TDICs ao cotidiano pedagógico acarretaria no desafio de se criar/ desenvolver novas formas de ensinar e aprender, que muitas vezes acabam esbarrando em determinadas práticas cristalizadas no contexto das diferentes culturas escolares. Então, ao partir-se do princípio de que tal integração envolveria supostamente uma redefinição do papel docente no processo, dando margem para uma nova postura dos alunos durante as aulas, poderia encontrar barreiras para a sua efetivação. Isso poderia ocorrer, principalmente, ao levar-se em consideração que essa mudança, quando entra para o contexto escolar, juntamente com as reformulações nas relações de ensino e aprendizagem, pode revelar tendências arcaicas nessas relações, gerando certo constrangimento e desconforto entre alguns docentes (PIRES et al., 2017).

Salienta-se, também, como expectativa, a necessidade de abordagens ligadas especificamente aos diferentes componentes curriculares, constituindo avanço no âmbito da formação docente, tendo em vista que, muitas vezes, as tematizações genéricas acerca da educação não dão conta de dialogar com, ou serem propositivas para, as diferentes práticas pedagógicas desenvolvidas no ambiente escolar. Por isso, foi relatado, com ares de surpresa, a presença de uma parte específica que dialogava diretamente com as

\footnotetext{
${ }^{8} \mathrm{~A}$ hora-atividade se estrutura de diferentes formas nos mais variados contextos estaduais e municipais Brasil afora, e, certamente, ainda não constitui uma realidade para todos os professores do país. Refere-se a um teç̧o da jornada semanal de trabalho dos professores, dedicado ao planejamento, estudo e formação continuada, conforme previsto na Lei 11.738/08, que institui o piso salarial profissional nacional para os profissionais do magistério público da educação básica.
} 
disciplinas escolares, da qual se tirou maior proveito para a atuação docente. De acordo com o professor/ cursista 6,

\begin{abstract}
"Quando nós iniciamos, a gente pensou que fosse algo, assim, mais no geral mesmo, que nós não teríamos nada específico na área [...] E uma coisa que me surpreendeu e que me deixou bastante feliz foi ter a parte específica de educação física, pois logo no início a gente não tinha entendido que teria. A gente achou que seria mais no geral, assim. E que isso também foi o maior ganho, nesse sentido, porque inovou bastante com outras possibilidades de utilizar as tecnologias na educação fisica...que antes eu também não via” (PC6).
\end{abstract}

Pelo depoimento desse professor/ cursista, sua primeira impressão era de que o curso contemplaria apenas a tematização da educação no contexto da cultura digital, a partir de uma abordagem genérica, que pensasse a escola e não propriamente as temáticas específicas ligadas aos diferentes componentes curriculares. Nessa perspectiva, é importante destacar uma das características do curso de especialização: a estruturação de núcleos de estudo pautados em reflexões com base em experiências concretas em âmbito escolar, dialogando com as especificidades dos diferentes componentes curriculares. Embora o mote central fosse a formação do coletivo escolar, as ações desenvolvidas nos núcleos permitiam aos cursistas, pois, diferentes percursos formativos moldados de acordo com as suas realidades escolares, necessidades e interesses (RAMOS et al., 2013). Esses diferentes percursos formativos estão relacionados com os distintos componentes curriculares a serem contemplados nas escolas, de acordo com os professores participantes do curso. No caso específico dos professores de Educação Física, foram abordadas possibilidades formativas de caracterização da Educação Física escolar enquanto componente curricular; relações com a mídia-educação; lazer, jogos e brincadeiras; esporte e suas novas vivências; e corpo, saúde e estética ${ }^{9}$.

Assim, a surpresa do professor entrevistado sobre a presença de um núcleo que contemplava a integração das TDICs, a partir do olhar da Educação Física escolar, parece ser um dado representativo das características das políticas públicas de formação continuada, ligadas às abordagens com as tecnologias, que nem sempre versam sobre as especificidades das áreas de conhecimento. Da mesma forma, deve-se também ao fato dos currículos tradicionais da formação inicial em licenciatura em Educação Física, em sua maioria, não contemplarem possibilidades formativas nas quais a Educação Física escolar poderia incorporar as TDICs ao seu fazer cotidiano. Um exemplo desse quadro é apresentado no estudo de Silveira,

\footnotetext{
${ }^{9}$ Para mais informações, ver: PIRES, G de L. (et al.). Educação (Física) na cultura digital: memória da produção de um curso na modalidade EaD. In: CERNY, R. Z.; RAMOS, E. M. F.; BRICK, E. M.; OLIVEIRA, A. dos S.; SILVA, M. R. da. (Org.). Formação de educadores na cultura digital: a construção coletiva de uma proposta. $1^{\text {a }}$ ed.Florianópolis: UFSC/CED/NUP, 2017, p. 125-155.
} 
Brüggemann e Bianchi (2019, p.15), sobre cursos de licenciatura em Educação Física nas Universidades Federais:

\begin{abstract}
Das sessenta e três (63) universidades investigadas, quarenta e quatro (44) ofertam curso de graduação em Educação Física - Licenciatura e destas, apenas vinte e um (21) cursos/ instituições apresentam componentes curriculares que versam sobre as TDIC/ mídia. [...] E, assim sendo, a ausência de componentes curriculares em mais de dois terços das instituições investigadas é reveladora de uma demanda a ser cumprida pela área visando qualificar a formação docente (SILVEIRA; BRÜGGEMANN; BIANCHI, 2019, p.15).
\end{abstract}

Uma expectativa bastante representativa nos depoimentos dos professores/ cursistas está atrelada à compreensão de que um curso de tecnologias na escola deveria ser pautado em uma abordagem instrumental, técnica ou operacional, concebendo as TDICs como ferramentas de inovação das aulas. Tal compreensão é destacada nos seguintes trechos de entrevistas:

"Eu esperava um curso um pouco mais técnico...tipo assim, ensinar a gente a utilizar algum aplicativo ou equipamento, mas necessariamente não foi tão nessa linha, foi mais na área pedagógica mesmo" (PC5).

"Então... a expectativa era realmente poder saber manusear mais as ferramentas tecnológicas, mas também, assim, saber lidar com aplicativos. Algo que a gente tinha muita dificuldade, né?! Inclusive, ainda hoje tem professores que não sabem ligar um Datashow...essas coisas assim” (PC6).

"Eu esperava bastante a parte técnica mesmo, operacional das tecnologias e como a gente aplicar isso no nosso cotidiano na escola e acabou sendo bem diferente do que eu previa, né?! Mas a minha expectativa era essa, assim, de aprender a lidar com a ferramenta mesmo, né?! A parte operacional" (PC7).

Tal dado se aproxima das constatações da pesquisa-ação realizada por Mendes (2009), na qual foi verificado que todos os participantes do estudo apresentavam expectativas de um uso instrumental das TDICs na Educação Física escolar, não ultrapassando a lógica da incorporação de um novo recurso didático às aulas.

Essa afirmação parece expor, assim, uma concepção ingênua do incremento de aparatos tecnológicos como responsável pela qualificação das ações pedagógicas, tornando, assim, o ensino melhor. Não há outro motivo para verificar a expectativa por aprender a utilizar algum equipamento ou aplicativo, passível de inovação das práticas pedagógicas, de acordo com as especificidades de seus componentes curriculares, transferindo a esses meios tecnológicos a responsabilidade por tornar as aulas mais atrativas e 
eficientes. Assim, o professor parece apostar "nas mídias como possibilidade de renovação didática, atribuindo a elas uma missão de transformação das práticas tradicionais" (MENDES, 2009, p.177).

Dessa maneira, percebe-se o conceito de mídia-educação ainda distante das formações docentes e, consequentemente, das salas de aula. A surpresa quanto a uma "abordagem pedagógica das TDICs" é uma das expressões máximas que indica o quanto ainda estamos longe de consolidar as possibilidades mídiaeducativas no cotidiano das escolas. De acordo com Bianchi (2010, p.226), "percebe-se a falta de [...] espaços na formação inicial e continuada quando se trata de propostas qualificadas e críticas na perspectiva das TICs, que apresentem interesse em preparar os professores para educar com, nas e para as TICs".

Assim, a educação na cultura digital deve avançar para além do aparelhamento técnico das instituições escolares, pautando-se na formação crítica dos sujeitos, concretizando-se no duplo desafio apresentado por Souto e Lapa (2014, p.91), de “educar e educar-se na cultura digital”, visando uma ruptura com o paradigma da transmissão, instrução e reprodução. Por isso, a importância dos docentes se apropriarem das TDICs instrumentalmente, mas também de forma crítica e criativa, repensando seus próprios métodos de ensino.

Ao levarmos em consideração os sujeitos entrevistados, professores de Educação Física, e o caráter recente da temática do curso, muitas vezes não contemplada na formação inicial nessa área específica, obteve destaque uma expectativa ligada às próprias relações entre Educação Física e TDIC na escola. Segundo o professor/ cursista 2,

“Assim ó, a princípio, quando eu comecei a fazer o curso, assim, um pouco mais foi a questão da curiosidade, porque eu não conseguia imaginar o uso das tecnologias nas aulas de educação física. [...] Diretamente na minha área eu não conseguia imaginar. E só durante o curso que eu comecei a perceber um caminho, uma abertura imensa, dá pra fazer um monte de coisa, mas realmente eu não tinha essa visão" (PC2).

É perceptível uma curiosidade ou mesmo dúvida por parte do docente entrevistado, ligadas ao desconhecimento das possíveis abordagens da Educação Física escolar com as tecnologias. Nesse caso específico, o professor/ cursista tinha uma compreensão de que não era possível integrar as TDICs nas aulas de Educação Física. Tal ponto de vista alicerça-se em uma visão hegemônica de Educação Física, muitas vezes restrita ao movimento e à realização de gestos técnicos nas aulas, em tempos e espaços bem demarcados, nas quadras, ginásios, etc., não deixando margem para uma abordagem problematizadora desse componente curricular, que compreenderia, além do saber fazer, o saber sobre o fazer e o saber por que fazer (GONZALEZ; FENSTENSEIFER, 2010). 
Outra possibilidade de análise perfeitamente razoável diz respeito às características das vivências tecnológicas cotidianas das crianças, a partir de uma compreensão partilhada no senso comum de que, hoje, as crianças não brincam, só querem tablet, celular, videogame e computador, não saem de casa, enfim, não se movimentam. Nesse caso, as aulas de Educação Física seriam compreendidas justamente como um tempo/ espaço que se constituiria como antagonista às vivências mediadas pelas tecnologias que acabam "destruindo" a infância contemporânea. Por isso, a dificuldade de se aceitar a ideia de uma Educação Física escolar integrada às TDICs, em seu fazer pedagógico.

É evidente que tal compreensão precisa ser relativizada, tomando como base uma concepção de Educação Física na qual o movimento humano seja adotado como objeto de intervenção para além de suas dimensões fisiológicas ou biomecânicas, abarcando um domínio simbólico, caracterizado como fenômeno cultural e histórico. Nessa perspectiva, as vivências digitais do esporte, por meios dos games (CRUZ JÚNIOR, 2012; PEREIRA; SILVA, 2016), por exemplo, podem ser compreendidas como complementares às práticas tradicionais do esporte em âmbito escolar, estabelecendo ricas possibilidades de interlocução, como a abertura de horizontes para a compreensão de aspectos extra campo/ quadra, muitas vezes imperceptíveis durante situações de fruição esportiva tradicional. Ou seja, é preciso abdicar de uma visão antagonista entre vivências tradicionais e eletrônicas, em nome de uma ressignificação do saber com/ sobre o movimento humano na contemporaneidade.

Nas relações entre Educação Física e TDIC, há uma preocupação ligada aos modos de integração das tecnologias ao cotidiano pedagógico das aulas de Educação Física. Para o professor/ cursista 8,

"Quando eu iniciei o curso, eu pensava uma coisa bem diferente, certo? Que eu ia trabalhar dentro do laboratório, que eu ia ficar lá junto com os alunos... que eu ia fazer mais ou menos isso, ia brincar"(PC8).

Vê-se uma compreensão da abordagem das tecnologias na escola implicada aos usos restritos ao laboratório de informática. Tal depoimento tende a ser representativo de um contexto, provavelmente, de proibição do uso de tecnologias em sala de aula (na escola como um todo), em que as únicas possibilidades de se trabalhar com internet ou computadores, por exemplo, estariam vinculadas a um espaço bem delimitado - o laboratório ou a sala de informática. É interessante notar uma determinada/ possível relação entre Educação Física escolar e as TDICs, por parte do professor, em que as formas de integração das tecnologias ao seu fazer pedagógico estariam restritas a um "brincar com as TDICs". Tal fato, além de revelador de uma determinada concepção de Educação Física e do seu papel nas escolas, indica o 
desconhecimento de como efetivamente pode ser proposta a mediação didático-pedagógica-tecnológica dos conteúdos desse componente curricular (BIANCHI, 2010).

Finalizando, ainda sobre as eventuais contribuições das TDICs para as aulas de Educação Física na visão dos professores/ cursistas entrevistados, havia a expectativa de uma preparação docente para um enfrentamento, no ambiente escolar, da compreensão do mau uso das tecnologias por parte das crianças. Seria necessário, portanto, uma integração das tecnologias pautadas em intencionalidade pedagógica, para se aprimorar o ensino. Conforme o professor/ cursista 10,

"A expectativa era realmente de como usar as tecnologias dentro da escola, pedagogicamente, né?! [...] No início a gente via as crianças usando de repente um computador, vendo utilizar um celular, mas sem fim de aprendizagem educacional, então eu tinha essa expectativa em fazer com que esses recursos realmente funcionassem dentro da escola no sentido de ensinar, contribuindo na aprendizagem dos alunos"(PC10).

Nesse caso, é perceptível um entendimento do uso das TDICs pelas crianças, na escola, em desacordo com a proposta formativa daquele ambiente educacional. Portanto, fazia-se necessária uma apropriação das tecnologias, que envolvesse intencionalidade pedagógica no uso das TDICs nas aulas, de maneira que pudessem contribuir para a aprendizagem dos alunos. De fato, essa é uma expectativa plausível, por considerar a apropriação das TDICs como meio para se ensinar numa perspectiva de ação docente na escola, exigindo que o professor esteja "preparado para integrar as TDICs à prática com intencionalidade pedagógica clara [...]”' (ALMEIDA, 2014, p. 29).

\section{Considerações finais}

É possível afirmar que a formação de professores possui caráter dinâmico, tendo em vista as demandas formativas desses profissionais, diretamente relacionadas às próprias características assumidas pela educação institucionalizada. Isso implica mudanças sociais e culturais, que impactam o cotidiano escolar e que acabam impondo, à educação, reformulações em termos de currículos e metodologias de ensino. Essa formação deve também contemplar as licenciaturas e a formação continuada dos trabalhadores da educação.

Nesse sentido, ao levarmos em conta a dinâmica cultural contemporânea, em grande medida alicerçada pelos usos das tecnologias digitais de informação e de comunicação, é possível vislumbrar 
facilmente algumas das exigências impostas à educação escolar, para que se reinvente e seja coerente com uma cultura digital. Daí, a importância de compreender como os professores lidam com essa mudança em processo, e como essas temáticas partem de seu percurso formativo, são encaradas por eles.

No presente exercício analítico, com os dados produzidos com professores de Educação Física, foi possível verificar uma série de preocupações quanto à tematização do seu componente curricular, à luz dos pressupostos teóricos de uma educação na cultura digital. Suas expectativas versaram sobre: a) a curiosidade quanto ao próprio conceito de cultura digital; b) o funcionamento de um curso na modalidade $\mathrm{EaD}$; c) a aceitação, pelos alunos e colegas, de práticas com a integração das TDICs na escola; d) o desejo por abordagens de demandas da Educação Física; e) as possibilidades de tematização da Educação Física com o suporte das TDICs; f) e o desenvolvimento de uma intencionalidade pedagógica das TDICs na escola.

Pode-se inferir, assim, expectativas e preocupações dos professores sobre abordagem pedagógica da Educação Física escolar, pautada no uso das tecnologias digitais de informação e comunicação, como indicativo importante das lacunas a serem preenchidas no âmbito da formação docente. Nesse sentido, é preciso que as licenciaturas e cursos de formação continuada pautem as relações entre esse componente curricular e as TDICs, possibilitando aos professores a apropriação desses meios na perspectiva de uma inovação curricular coerente com as demandas da educação contemporânea.

Para tal, defende-se uma perspectiva de formação docente incorporadora da mídia-educação às matrizes curriculares, de modo a possibilitar o desenvolvimento de propostas educativas com, para e através das mídias/ TDICs (FANTIN, 2006). Assim sendo, propõe-se que os professores de Educação Física se apropriem instrumentalmente das tecnologias, visando superar medos e inseguranças no uso pedagógico. Da mesma forma, almeja-se que desenvolvam possibilidades de se produzir e partilhar conhecimentos através desses meios, no intuito de uma prática pedagógica criativa e colaborativa. E também possam compreender criticamente o papel que essas ferramentas desempenham cotidianamente no que tange a circulação de informações e como filtrar criticamente esses conteúdos na perspectiva de uma formação emancipada.

Por fim, ao considerarmos o momento histórico atual, marcado pela Pandemia de Covid-19, é notável a demanda por uma apropriação tecnológica da parte dos docentes, em termos de uma reinvenção didática, tendo em vista a necessidade do ensino remoto. Tal fato tende, por um lado, a expor o quanto a imposição do uso das TDICs, sem a necessária formação e infraestrutura, pode gerar rupturas e problemas para os professores em suas práticas pedagógicas. Por outro lado, essa realidade pode reforçar a necessidade de uma formação docente pautada nos princípios da mídia-educação, conforme as concepções e expectativas docentes, expostas no presente artigo, permitiram constatar. 


\section{Referências}

ALMEIDA, M. E. B. Integração currículo e tecnologias: concepção e possibilidades de criação de web currículo. In: ; ALVES, R. M.; LEMOS, S. D. V. (Org.). Web currículo: aprendizagem, pesquisa e conhecimento com o uso de tecnologias digitais. Rio de Janeiro: Letra Capital, 2014. p. 20-38. Disponível em: 〈http://revistas.pucsp.br/index.php/curriculum/article/viewFile/5676/4002>. Acesso em: ago. 2014.

BARDIN, L. Análise de conteúdo. 4ª Edição. Lisboa/Portugal: Edições 70 Lda, 2009.

BIANCHI, P. Relato de Experiência em mídia-educação (Física) com professores da rede municipal de ensino de Florianópolis/SC. In: PIRES, G. De L.; RIBEIRO, S. D.(Org.). Pesquisa em Educação Física e Mídia: contribuições do LaboMídia/UFSC. 1ed.Florianópolis: Tribo da Ilha, 2010, v. 1, p. 226-247.

BIANCHI, P. Formação de professores e cultura digital: observando caminhos curriculares através da mídia-educação. 2014. 302p. Tese (Doutorado em Educação Física). Programa de Pós-Graduação em Educação Física. Universidade Federal de Santa Catarina, Florianópolis, 2014.

BUCKINGHAM, D. Precisamos realmente de educação para os meios? In: Comunicação e Educação. São Paulo. Ano XVII. $\mathrm{N}^{\circ}$ 2, jul/dez 2012. p.41-60. Disponível em: http://www.revistas.usp.br/comueduc/article/view/73536/77235. Acesso em: novembro de 2015.

CARVALHO JUNIOR, J. M. Por uma cultura digital participativa. In: SAVAZONI, R.; COHN, S. (Orgs.). Cultura digital.br. Rio de Janeiro: Beco do Azougue, 2009. p.09-12.

CRUZ JÚNIOR, G. Eu jogo, tu jogas, nós aprendemos: experiências culturais eletrolúdicas no contexto do ciberespaço. 2012. 245p. Dissertação. (Mestrado em educação). Faculdade de Educação. Programa de Pós-Graduação em Educação. Universidade Federal de Santa Catarina. 2012.

FANTIN, Mônica. Mídia-educação: conceitos, experiências, diálogos Brasil-Itália. Florianópolis: Cidade Futura, 2006.

FREITAS, Maria Teresa de Assunção. A perspectiva sócio-histórica: uma visão humana da construção do conhecimento. In: FREITAS, M. T.; SOUZA, S. J. e.; KRAMER, S. (Orgs.). Ciências humanas e pesquisa: leituras de Mikhail Bakhtin. São Paulo: Cortez, 2007. p.26-38.

GONZALES, F. J.; FENSTERSEIFER, P. E. Entre o "não mais" e o "ainda não": pensando saídas do nãolugar da educação física escolar II. Cadernos de formação do CBCE, v. 1, n.2, 2010. Disponível em: http://www.rbceonline.org.br/revista/index.php/cadernos/article/view/978

MENDES, D. S. Luz, câmera e pesquisa-ação: a inserção da mídia-educação na formação continuada de professores de Educação Física. 2009. 148p. Dissertação (Mestrado em Educação Física), Programa de Pós-Graduação em Educação Física, Centro de Desportos. Universidade Federal de Santa Catarina, 2009.

MINAYO, M.C. de S. O desafio da pesquisa social. P. 09-29. In: Minayo M. C. de S. (Org.). Pesquisa Social: teoria, método e criatividade. $31^{\text {a }}$ Edição. São Paulo: Vozes, 2012, 108p. 
PEREIRA, R. S.; SILVA, S. R. Aprender a chutar com as mãos: jogos eletrônicos e o ensino do futebol. In: Silvio Ricardo da Silva; Leandro Batista Cordeiro; Priscila augusta Ferreira Campos. (Org.). O ensino do futebol: para além da bola rolando. 1ed.Rio de Janeiro: Jaguatirica, 2016, v., p. 197-218.

PIRES, G de L. (et al.). Educação (Física) na cultura digital: memória da produção de um curso na modalidade EaD. In: CERNY, R. Z.; RAMOS, E. M. F.; BRICK, E. M.; OLIVEIRA, A. dos S.; SILVA, M. R. da. (Org.). Formação de educadores na cultura digital: a construção coletiva de uma proposta. $1^{\text {a}}$ ed.Florianópolis: UFSC/CED/NUP, 2017, p. 125-155.

PIRES, G. De L.; LAZZAROTTI FILHO, A; LISBOA, M. M.; Educação Física, mídia e tecnologias: incursões, pesquisa e perspectivas. Santa Maria, Kinesis, v. 30, n.1, 2012, p.55-79. DOI: http://dx.doi.org/10.5902/010283085723

PRETTO, N. P.; ASSIS, A. Cultura digital e educação: redes já! In: PRETTO, N L.; SILVEIRA, S.A (org.). Além das redes de colaboração: internet, diversidade cultural e tecnologias do poder. Salvador: EDUFBA, 2008, p. 75-83.

RAMOS, E. M. F. (et al.) Curso de especialização em educação na cultura digital: documento base. Brasília: Ministério da Educação, 2013-a. Disponível em: educacaonaculturadigital.mec.gov.br/downloads/documento-base.pdf. Acesso em setembro de 2015.

SILVEIRA, Juliano; BRÜGGEMANN, Ângelo Luiz; BIANCHI, Paula. Formação de professores de Educação Física e tecnologias digitais de informação e comunicação (TDIC)/mídia: uma relação possível? Análise das propostas curriculares de universidades federais brasileiras. Motrivivência, Florianópolis, v. 31, n. 57, mar. 2019. ISSN 2175-8042. Disponível em: 〈https://periodicos.ufsc.br/index.php/motrivivencia/article/view/2175-8042.2019e55308/39009>. Acesso em: 15 abr. 2020. doi:https://doi.org/10.5007/2175-8042.2019e55308

SOUTO, I. N.; LAPA, A. B. Formação crítica mediada pelas tecnologias digitais de informação e comunicação: um desenho de pesquisa qualitativa. In: Comunicação \& Informação, Goiânia, GO, v. 17, n. 2, p. 88-103, jul./dez. 2014. Disponível em https://www.revistas.ufg.br/ci/article/view/31836/17613. Acesso em: 25 de outubro de 2015.

\section{Como citar este artigo}

SILVEIRA, J.; PIRES, G.L. Reflexões sobre as concepções e expectativas de professores de Educação Física acerca de um curso de especialização em educação na cultura digital. Revista Kinesis, Santa Maria, v. 39, p.01-15, 2021.

* O presente trabalho não contou com apoio financeiro de nenhuma natureza para sua realização. 